\title{
Terrestrial free space optical communications in bangladesh: transmission channel characterization
}

\author{
Kazi Shahiduzzaman', Majumder F. Haider², Bijoy K. Karmaker ${ }^{3}$ \\ ${ }^{1,3}$ Department of Electrical and Electronic Engineering, Jatiya Kabi Kazi Nazrul Islam University, Bangladesh \\ ${ }^{2}$ Department of Electrical and Electronic Engineering, BRAC University, Bangladesh
}

\begin{abstract}
Article Info
Article history:

Received May 18, 2018

Revised Mar 29, 2019

Accepted Apr 8, 2019

\section{Keywords:}

Atmospheric attenuation Channel characterization Free space optical Optical turbulence Optical wireless communication

ABSTRACT

This research work focused on transmission channel characterization of FreeSpace-Optical (FSO) communications technology for deploying in the developing country like Bangladesh. To meet the tremendous amount of data traffic, mobile operators and ISPs need better solution than the existing RF and fiber optic communications. Moreover, Bangladesh is entering in the era of satellite communications by launching its own satellite. So, Bangladesh needs such communication technology that provides higher channel bandwidth, sophisticated transmission security and can cope channel dispersion. FSO is a good candidate that can meet all these features. The transmission channel characterization plays a significant role in optimizing the performance of FSO link. In this work, the channel characterization of FSO technology from the weather perspective of Bangladesh has been investigated thoroughly. The obtained results show that the atmospheric scattering effect does not hamper the short range FSO link performance, whereas, the atmospheric turbulence effect is not favorable to deploy FSO technology with reasonable quality signal unless it is optimized properly using antenna aperture averaging technique.
\end{abstract}

Copyright () 2019 Institute of Advanced Engineering and Science. All rights reserved.

\section{Corresponding Author:}

Kazi Md Shahiduzzaman, Department of Electrical and Electronic Engineering, Jatiya kabi Kazi Nazrul Islam University, Trishal, Mymensingh, Bangladesh.

Email: shahiduzzaman@jkkniu.edu.bd

\section{INTRODUCTION}

The volume of using smart phone applications and the number of internet users are increasing rigorously day by day. In the developing countries like Bangladesh, the demand of surfing very high speed internet and using smart phone's heavy applications are increasing enormously. To meet the increasing demand existing communication technologies like microwave communication, optical fiber technology are not capable enough considering ultra-high speed data, less interference, data transmission security and cost effectiveness. Thus, it requires the implementation of such an effective technology that is efficient to handle the increasing demand and overcome the limitations of existing technologies in the foreseeable future. Free-Space-Optical (FSO) is an optical communication technique that transmits data wirelessly for terrestrial and space communication systems through the propagation of the laser light in free space air [1]. FSO communication is the vital and most modern technology for the future ultra-high speed and huge capacity enabled mobile \& data communication systems. FSO provides huge data rate than existing RF technology for wireless communication systems [1]. FSO operates between 780-1600 nm wavelength bands that allow optical communication without requiring fiber optic cable and licensed frequency spectrum [1].

The existing RF communication has limited licensed frequency spectrum, which is very expensive and hence, cannot offer huge data capacity. Moreover, the existing backbone networks of mobile phone operators are formed using optical fiber technology that increases the cost significantly [2]. In contrast, FSO 
communication provides some additional advantages like FSO provides no dispersion loss to the optical signal which is a major concern in optical fiber communication [3]. The launching power of typical optical fiber is limited to few $\mathrm{mW}$ which can be overcome by using inline amplification or regeneration. However, FSO uses transmitter power, antenna gain, bandwidth expansion and sensitive receiver to overcome the channel loss [4-5]. Optical fiber technology provides high data rates with less data transmission security but FSO can provide ultra-high speed data rate with high data transmission security through transmitting the laser having narrow beam that is very much suitable for wireless data transfer in financial, legal, military and other sensitive information systems [3]. FSO also requires less mass and volume of equipment [6] in case of deployment, less diffraction and uses basic modulation technique which makes the transmitter design less complicated over existing RF communication $[4,7]$. These properties make FSO a promising technology for next generation communication systems.

FSO communication includes a wide range of short and long distance wireless applications [8-9]. FSO system comprises with three major parts named transmitter that sends information in terms of optical signal using LED or Laser diode, then the signal propagates through free space transmission channel where air is the media and finally the receiver that receives the optical signal using photodiode to extract the original information [6]. This research work focuses to characterize the transmission channel characteristics of FSO link considering the weather conditions of Bangladesh to determine the feasibility of the deployment of this emerging technology.

The rest of the paper is outlined as follows. Section 2 discussed about a brief description of FSO technology and its deployment impairment. The atmospheric impact on FSO link performance has been described in section 3. The atmospheric attenuation effects in different weather conditions have been illustrated along with tabular data and graphs in section 4. The outcomes of this work and possible future work have been mentioned as conclusion in section 5 .

\section{OVERVIEW OF FSO TECHNOLOGY}

The following Figure 1 represents the operational principle of FSO communication. There is a laser diode (LD) or a light emitting diode (LED) as the source of light, a modulator, a drive circuit for the light source to supply necessary power and a telescope for transmitting light in most of the transmitter used for FSO communication $[6,7,10]$. The modulator converts the bits of information into an electrical signal and modulates the light source to generate an optical signal depending on the modulation format. This modulated beam passes through a telescope (collimating lens) to expand the optical beam which reduces the diffractive effect that spread out the beam [10]. Then, the transmitted optical beam propagates through atmospheric channel, where it suffers some physical processes inherent to atmosphere like frequencyselective absorption, scattering, turbulence and sporadic misalignment of transmitter and receiver due to displacement [3]. The propagated signal is then collected by a receiver, which consists of a telescope, a matched optical filter, a decoder and a detector to get the output signal. The main purpose of the telescope is to collect the optical signal and to form the beam size small enough to fit into the detector [10].

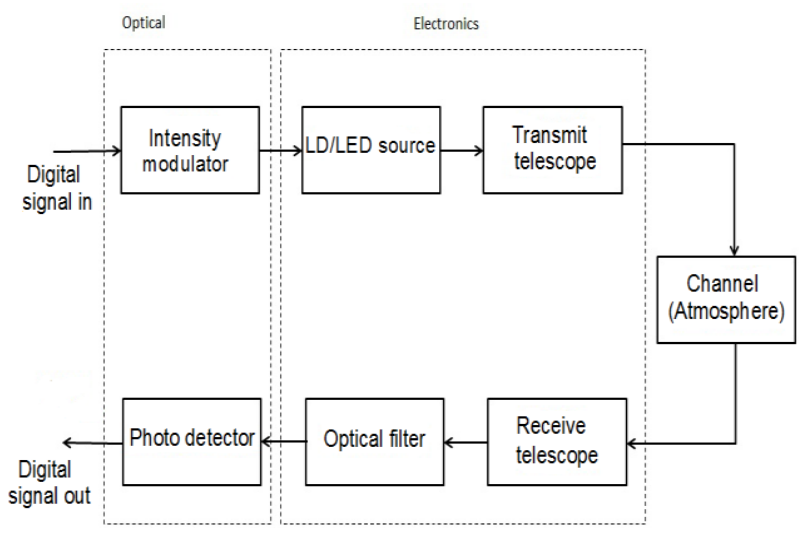

Figure 1. Typical block diagram of FSO communication systems

There is always a tradeoff among channel length, bit rate and error performance during designing the communication systems. In FSO communication, the link performance is truly influenced by weather conditions, the signal degradation caused by weather is known as atmospheric attenuation effects $[4,11,12]$. 
The most common atmospheric attenuation factors are beam divergence, absorption, scattering and refractive turbulence $[4,11]$. In the following sections, the impact of atmospheric attenuation on FSO link performance to measure the feasibility of FSO link deployment is highlighted and theoretical assumptions are made.

\section{IMPACTS OF ATMOSPHERE ON FSO}

The atmosphere contains molecules like Nitrogen, Oxygen, Water and Carbon dioxide. Beside aerosols like haze, fog, dust, soil etc are also present in the atmosphere. All these molecules and aerosols contribute attenuation to wave travels through the free space. By definition the atmospheric attenuation is a process through which some or all electromagnetic energy is lost during propagation. There are three basic phenomenon, namely, absorption, scattering and atmospheric turbulence which add attenuation during the propagation [4, 12]. In case of optical signal propagation through free space the effect of absorption is negligible due to selective wavelength [1, 13, 14]. Absorption has a very little effect when the wavelength is in between $780 \mathrm{~nm}$ to $1662 \mathrm{~nm}$ [15]. Moreover, the wavelength $1550 \mathrm{~nm}$ offers some additional advantages [16], hence, the nominated wavelength in this work is $1550 \mathrm{~nm}$. Therefore, it can be assumed that the atmospheric attenuation is contributed by scattering and turbulence effect only [11, 12].

\subsection{Scattering effect on FSO}

Due to the physical interaction among travelling electromagnetic wave, molecules and aerosols presented in the environment a dispersal of a beam of radiation in different direction is known as scattering [4]. A very crucial parameter to determine the nature of scattering is characteristic size parameter $x_{0}=2 \pi r / \lambda$ where $r$ is the radius of the aerosol particle and $\lambda$ is the operating wavelength of the optical signal [16]. As typical wavelength used in FSO is in $\mu \mathrm{m}$ range so there is no logical reason of $x_{0}$ to be varied much less than 1 . The typical value is either $x_{0} \approx 1$ or $x_{0} \gg 1$ [16]. Thus, the atmospheric attenuation due to scattering can be computed by Mie scattering theory when $x_{0} \approx 1$ and Non-Selective (Geometrical optics) scattering when $x_{0} \gg 1$ [17]. During the winter season, when the number of foggy days increases the optical signal in free space may be scattered heavily in Bangladesh. Mie scattering is applicable when fog and haze droplets exist in the atmosphere. The scattering coefficient is computed by $[13,15,17]$.

$$
\beta_{\text {mie }}=\left(\frac{3.91}{V}\right)\left(\frac{0.55 \mu m}{\lambda}\right)^{i}[\mathrm{~dB} / \mathrm{km}]
$$

Here, $V$ is visibility range in $\mathrm{km}, \lambda$ is the incident wavelength in $\mu \mathrm{m}$ and $i$ is the size distribution of the scattering particles, typically varies from 0.7 to 1.6 depending on the visibility condition in terms of range [16]. When the particle size is much larger compare to the wavelength of the operating signal the scattering occurs due to the non-selective or geometrical scattering. In Bangladesh rain may cause this type of scattering during rainy season. The scattering coefficient due to non-selective scattering is [18].

$$
\beta_{\text {nonselective }}=\pi a^{2} N_{a} Q_{\text {scat }}\left(\frac{a}{\lambda}\right)
$$

Here, $a$ is the radius of raindrop in $\mathrm{cm}, N_{a}$ is the raindrop distribution in $\mathrm{cm}^{-3}$ and $Q_{\text {scat }}$ is the scattering coefficient which has usual value of 2 [18].

\subsection{Atmospheric turbulence}

The temperature above the earth surface becomes cooler as the altitude increases from the surface. This is because of release of solar radiation by the earth. That causes random change in refractive index $[7,19]$. Addition to solar radiation, because of the variation of pressure and wind speed the refractive index also shows similar property. This inconsistent characteristic of refractive index causes atmospheric turbulence and can be viewed as discrete cells or eddies of different temperature acting like a refractive prism [7]. It causes wave front distortion by phase shifting of the propagating optical signal and intensity distortion. But between these two types of distortion, intensity distortion is the most significant and known as scintillation [15]. The effect of atmospheric turbulence becomes mostly indicative in the midday or mid night due to the maximum temperature difference created at these times allthough turbulence effect degrades the optical signal quality throughout whole day. The atmospheric turbulence loss caused by scintillation is proposed by Rytov and recommended by ITU is given as follows [15]:

$$
\rho(L)=2 \times \sqrt{23.17 \times k^{7 / 6} \times \times C_{n}^{2} \times L^{11 / 6}}(\mathrm{~dB})
$$


Here, $k$ is the optical wave number, $L$ is the link length in $\mathrm{km}$ and $C_{n}^{2}$ is the refractive index structure parameter (RISP) in $\mathrm{m}^{-2 / 3}$. The typical value of RISP $C_{n}^{2}$ is 1.3 for planer wave and 0.5 for spherical wave [18]. Basically it depends on the geographical location (altitude above sea level) and wind speed. A common and widely used model to determine this is Hufnagel-Valley $(\mathrm{H}-\mathrm{V})$ model $[13,14,15]$.

\section{TYPICAL WEATHER CONDITION IN BANGLADESH}

As the atmospheric attenuation and turbulence is dependent largely on the weather conditions mainly visibility, rainfall and wind speed [20,21], our concern is on analyzing the feasibility of FSO technology in Bangladesh. Therefore, it becomes essential to test the weather impacts on FSO signal performance from the perspective of Bangladesh. For this purpose, seven cities of different regions named Dhaka, Rajshahi, Chittagong, Sylhet, Rangpur, Mymensingh and Barisal in Bangladesh have been selected and comply for the investigation. The reason behind selecting these cities not only because of their different weather and atmospheric diversity but also the result will represent the prospects of deploying this evolving technology here in Bangladesh.

The data of visibility from January 2013 to June 2016 is collected from the Bangladesh Meteorological Department (BMD) [22]. The data of visibility have been used to determine the Mie scattering effect. As Bangladesh faces not only heavy rainfall every year during monsoon, but also light to medium rainfall throughout the year. The rainfall data is also collected from BMD for the same tenure and same locations. But for calculating the atmospheric turbulence only data of wind speed from January 2013 to December 2015 is accessible for the same locations with the corresponding altitude.

\subsection{Scattering coefficient due to mie and rainfall}

The visibility data and the rainfall data are used to determine the total scattering coefficient. In case of analyzing visibility and rainfall data, monthly data from January 2013 to June 2016 has been accessed and calculated the maximum, minimum and average visibility and rainfall rate to analyse different condition like clear sky to worst case condition. First, the effect of Mie Scattering has been considered. The visibility has a direct effect on Mie Scattering. Figure 2 shows the change in visibility over time for the selected seven cities. Among the seven cities Rajshahi shows best result where the average visibility is more than $6 \mathrm{~km}$,

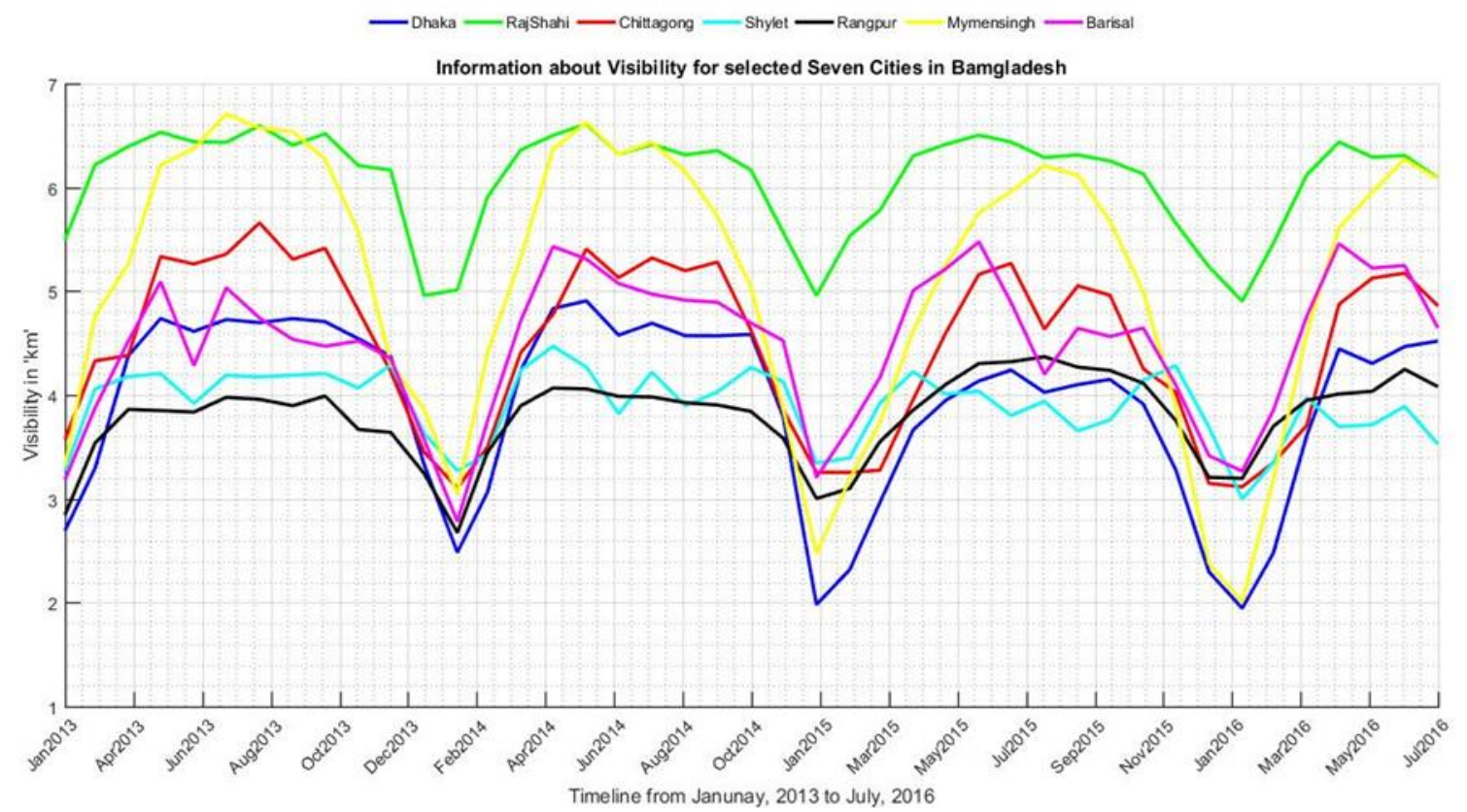

Figure 2. Change in visibility over time

while the maximum and minimum visibility are 6.6 and $5 \mathrm{~km}$ respectively. The visibility pattern of Mymensingh varies sharply during the whole year. Mymensingh reaches to the maximum visibility around 7 $\mathrm{km}$ around June and July each year then starts to fall and reaches to around $2 \mathrm{~km}$ in the winter season. Rangpur and Sylhet show the lower visibility pattern with an average visibility of $3.7922 \mathrm{~km}$ and $3.9015 \mathrm{~km}$

Terrestrial free space optical communications in bangladesh: transmission channel... (Kazi Shahiduzzaman) 
respectively. It is seen from Figure 2 that during the month between April to October all other cities except Mymensingh maintain maximum visibility. At the beginning of the winter season (November) the visibility starts to decrease and the worst visibility condition appears during January to February each year in all over Bangladesh. As the visibility has direct impact on determining the Mie Scattering, so the Table 1 presents maximum, minimum and average visibility range, and Mie scattering coefficient for the selected seven cities.

Table 1. Mie scattring coefficient analysis among the selected cities

\begin{tabular}{|c|c|c|c|c|c|c|}
\hline Cities & $\begin{array}{c}\text { Average } \\
\text { Visibility } \\
(\mathrm{km}) \\
\end{array}$ & $\begin{array}{c}\text { Maximum } \\
\text { Visibility } \\
(\mathrm{km}) \\
\end{array}$ & $\begin{array}{c}\text { Minimum } \\
\text { Visibility } \\
(\mathrm{km}) \\
\end{array}$ & $\begin{array}{c}\text { Average Mie } \\
\text { Coefficient } \\
(\mathrm{dB} / \mathrm{km})\end{array}$ & $\begin{array}{c}\text { Min Mie } \\
\text { Coefficient } \\
(\mathrm{dB} / \mathrm{km})\end{array}$ & $\begin{array}{c}\text { Max Mie } \\
\text { Coefficient } \\
(\mathrm{dB} / \mathrm{km}) \\
\end{array}$ \\
\hline Dhaka & 3.905212 & 4.906452 & 1.9451 & 0.38565 & 0.284676 & 0.943451 \\
\hline Chittagong & 4.482219 & 5.658 & 3.1032 & 0.321283 & 0.234816 & 0.520669 \\
\hline Shylet & 3.901533 & 4.47 & 2.9967 & 0.386129 & 0.322454 & 0.54471 \\
\hline Rangpur & 3.792212 & 4.3677 & 2.6741 & 0.400845 & 0.332545 & 0.630595 \\
\hline
\end{tabular}

From Table 1, it is clearly seen that cities with lower visibility show higher Mie scattering coefficient hence higher atmospheric attenuation. The attenuation due to Mie scattering is maximum in Dhaka, Rangpur and Sylhet. The average Mie scattering coefficients of these cities are $0.38565 \mathrm{~dB} / \mathrm{km}$, $0.400845 \mathrm{~dB} / \mathrm{km}$ and $0.386129 \mathrm{~dB} / \mathrm{km}$ respectively. While Rajshahi and Mymensingh show lower Mie scattering coefficient which are $0.213042 \mathrm{~dB} / \mathrm{km}$ and $0.270735 \mathrm{~dB} / \mathrm{km}$. From Table 1 , it can be easily considered the average visibility range for all over Bangladesh is around $4 \mathrm{~km}$. One more point can be noted that Dhaka and Mymensingh show worst Mie scattering effect (maximum Mie scattering coefficient are $0.943451 \mathrm{~dB} / \mathrm{km}$ and $0.907468 \mathrm{~dB} / \mathrm{km}$ ). While the city of Chittagong and Barisal can be considered as moderately Mie scattering affected areas.

Another dominant scattering factor for Bangladesh is rain. The rain profile for the selected cities has been plotted in Figure 3. Most of the rainfall occurs in between April to October each year. During the winter season the rainfall decreases but there is heavy fog in the atmosphere. Analyzing the rainfall data, it is found that Chittagong and Sylhet are the places where medium rainfall occurs. On the other hand, the amount of rainfall in Rajshahi, Rangpur, Dhaka, Mymensingh and Barisal can be considered as light rainfall region. Table 2 represents all rainfall data for the selected seven cities and also provides information about scattering loss due to rain respectively.

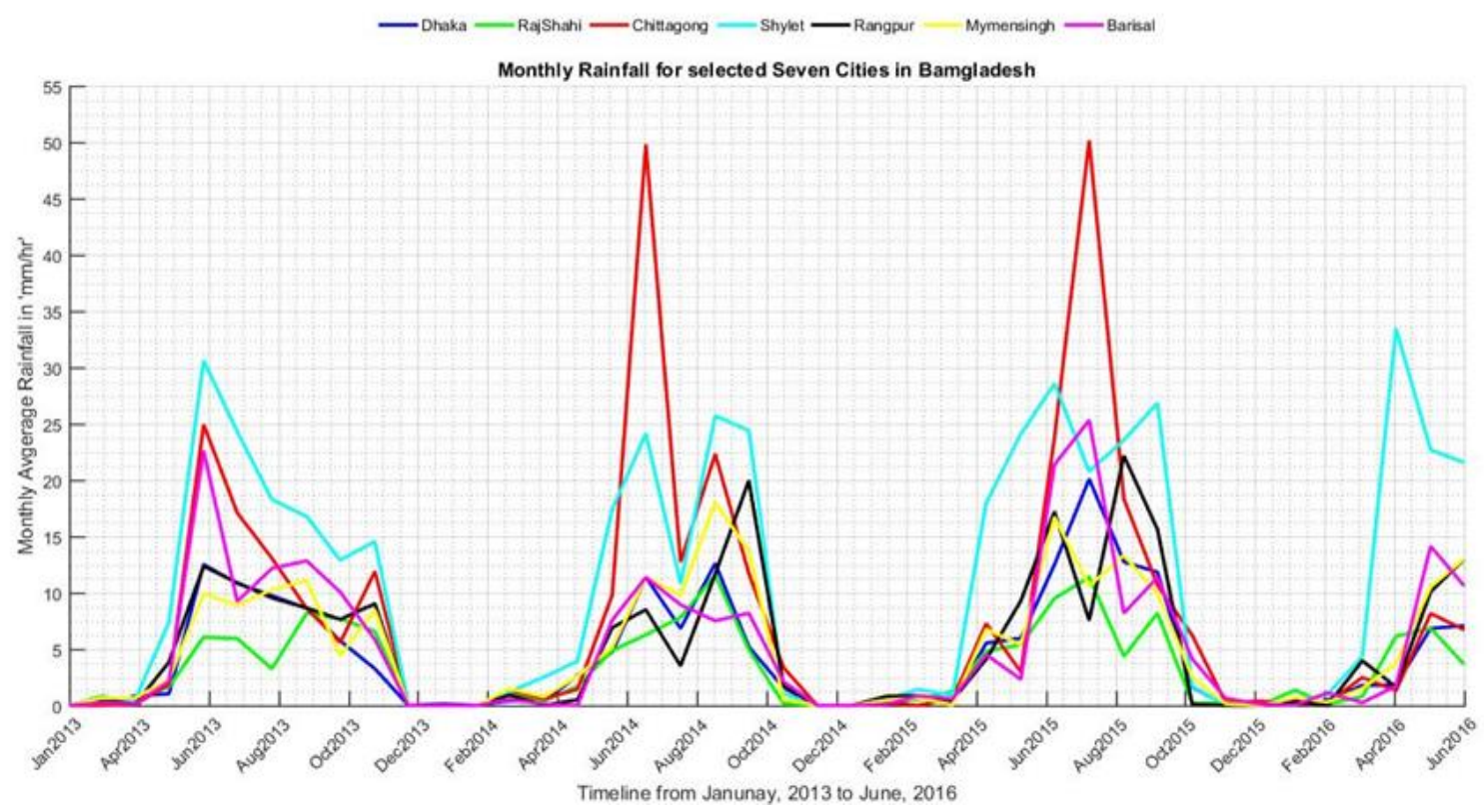

Figure 3. Rainfall for the selected seven cities of Bangladesh 
Table 2. Non-selective scattering due to rainfall

\begin{tabular}{lcccc}
\hline Cities & $\begin{array}{c}\text { Average rainfall in } \\
\mathrm{mm} / \mathrm{hr}\end{array}$ & $\begin{array}{c}\text { Maximum rainfall in } \\
\mathrm{mm} / \mathrm{hr}\end{array}$ & $\begin{array}{c}\text { Average Non-Selective Coefficient } \\
(\mathrm{dB} / \mathrm{km})\end{array}$ & $\begin{array}{c}\text { Max Non-Selective } \\
\text { Coefficient }(\mathrm{dB} / \mathrm{km})\end{array}$ \\
\hline Dhaka & 4.47 & 20.10 & 2.015 & 8.539 \\
Rajshahi & 3.44 & 11.58 & 0.869 & 6.145 \\
Chittagong & 8.00 & 50.16 & 4.539 & 12.512 \\
Sylhet & 11.11 & 33.47 & 5.965 & 10.754 \\
Rangpur & 5.32 & 22.16 & 2.769 & 8.964 \\
Mymensingh & 5.15 & 18.03 & 2.629 & 8.068 \\
Barisal & 5.45 & 25.32 & 2.873 & 9.543 \\
\hline
\end{tabular}

In calculating the scattering coefficient, the wavelength of the optical signal is considered as 1550 $\mathrm{nm}$ and the raindrop size is $0.003 \mathrm{~cm}$. As Sylhet is in hilly region of Bangladesh and affected by rain, this city possesses most non-selective attenuation coefficient on an average (around $6 \mathrm{~dB} / \mathrm{km}$ ). The maximum rainfall occurs in Chittagong, so the worst scattering effect caused by rain seen in that city (more than $12 \mathrm{~dB} / \mathrm{km}$ with an average of $4.539 \mathrm{~dB} / \mathrm{km}$ ). Meanwhile, the city of Rajshahi shows minimum non-selective scattering attenuation profile which has a coefficient of only $0.869 \mathrm{~dB} / \mathrm{km}$. One important outcome of this calculation is that all other cities of consideration have an average scattering coefficient from 2 to $3 \mathrm{~dB} / \mathrm{km}$. From the above analysis, it can be easier to consider the average link length and attenuation profile due to scattering for these cities. Table 3 shows the overall average scattering coefficient for the selected cities. It is clearly observed from the Table 3 that the dominant scattering factor is due to rain for all cities. Mie scattering plays comparatively small role in scattering attenuation.

Table 3. Total scattering coefficient for the selected cities

\begin{tabular}{lcccc}
\hline Cities & $\begin{array}{c}\text { Average Link } \\
\text { Length }(\mathrm{km})\end{array}$ & $\begin{array}{c}\text { Average Mie Coefficient } \\
(\mathrm{dB} / \mathrm{km})\end{array}$ & $\begin{array}{c}\text { Average Non-Selective } \\
\text { Coefficient }(\mathrm{dB} / \mathrm{km})\end{array}$ & $\begin{array}{c}\text { Total Scattering Coefficient } \\
(\mathrm{dB} / \mathrm{km})\end{array}$ \\
\hline Dhaka & 3.90 & 0.385 & 2.015 & 2.4 \\
Rajshahi & 6.07 & 0.213 & 0.869 & 1.172 \\
Chittagong & 4.48 & 0.321 & 4.539 & 4.860 \\
Sylhet & 3.90 & 0.386 & 5.965 & 6.351 \\
Rangpur & 3.79 & 0.400 & 2.769 & 3.169 \\
Mymensingh & 5.09 & 0.270 & 2.629 & 2.899 \\
Barisal & 4.48 & 0.320 & 2.873 & 3.193 \\
\hline
\end{tabular}

\subsection{Atmospheric turbulence effect}

Atmospheric turbulence effect causes beam steering, beam divergence and scintillation effect that degrades the performance of FSO link significantly $[16,17]$. The optical turbulence is the result of variation of refractive index in the atmosphere. The variation of temperature in the atmosphere causes the variation of refractive index [17]. Temperature changes due to change of altitude and wind speed in the atmosphere [23]. Thus, altitude and wind speed are the crucial factors that determine the severity of the atmospheric turbulence effect. The variation of wind speed for the year 2013 to 2015 has been plotted in Figure 4 based on the data collected for the selected seven cities.

Figure 4 demonstrates that average wind speed is $1.085 \mathrm{~m} / \mathrm{s}, 1.151 \mathrm{~m} / \mathrm{s}, 3.263 \mathrm{~m} / \mathrm{s}, 1.093 \mathrm{~m} / \mathrm{s}, 1.564$ $\mathrm{m} / \mathrm{s}, 0.997 \mathrm{~m} / \mathrm{s}$ and $0.884 \mathrm{~m} / \mathrm{s}$ for Dhaka, Rajshahi, Chittagong, Sylhet, Rangpur, Mymensingh and Barisal respectively. It is also observed that maximum average wind speed is for Chittagong where altitude is $15 \mathrm{~m}$ and minimum average wind speed is for Barisal where altitude is $4 \mathrm{~m}$. All the calculated results are arranged in the following Table 4. 


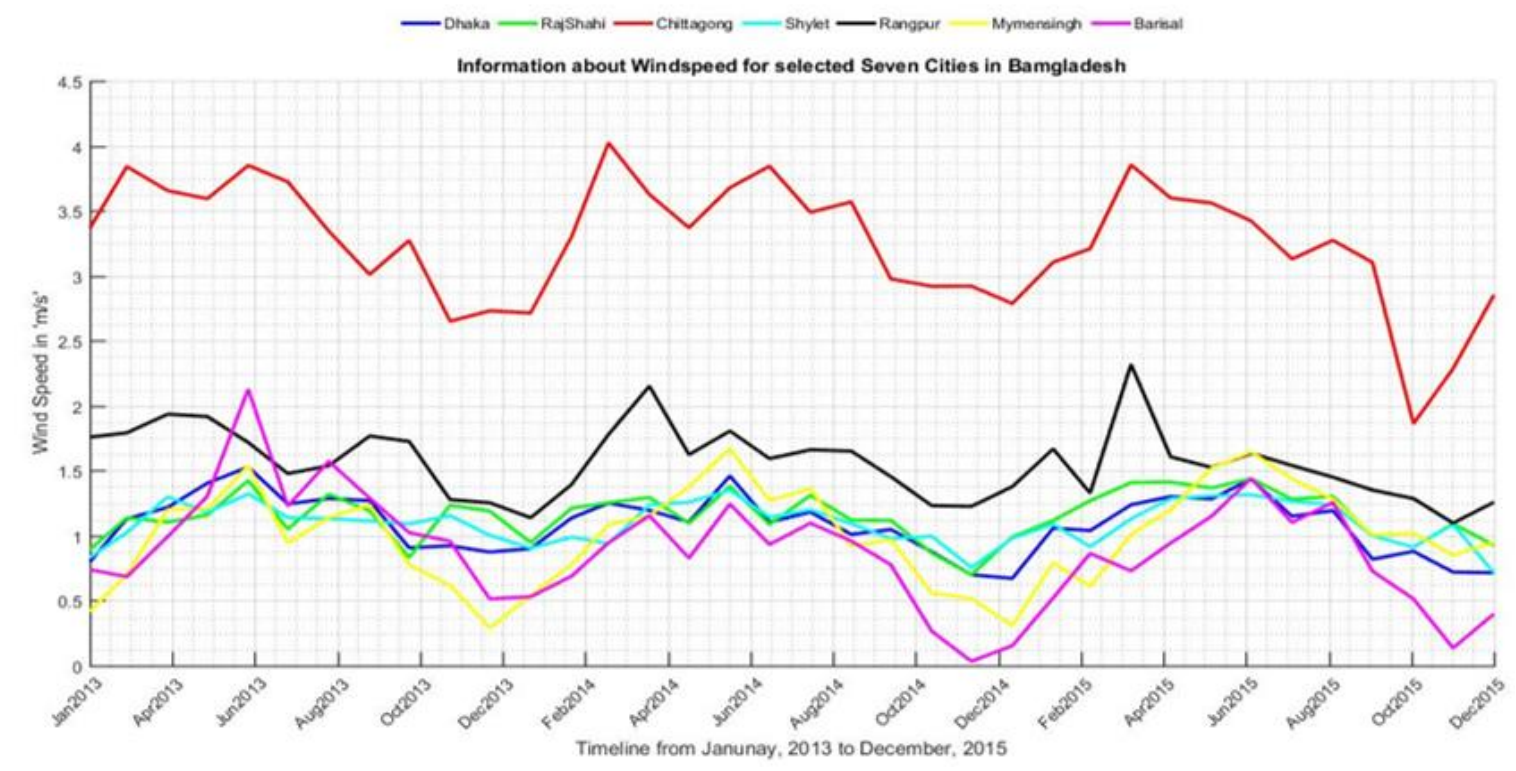

Figure 4. Wind speed profile for the selected seven cities

Table 4. Attenuation due to atmospheric turbulence

\begin{tabular}{|c|c|c|c|c|c|c|c|c|c|}
\hline Cities & $\begin{array}{l}\text { Altitude } \\
\text { (m) }\end{array}$ & $\begin{array}{c}\text { Average } \\
\text { Wind Speed } \\
(\mathrm{m} / \mathrm{s})\end{array}$ & $\begin{array}{l}\text { Maximum } \\
\text { Wind Speed } \\
(\mathrm{m} / \mathrm{s})\end{array}$ & $\begin{array}{c}\text { Average } \\
\text { scintillation } \\
\text { attenuation }(\mathrm{dB})\end{array}$ & $\begin{array}{c}\text { Average } \\
\text { scintillation } \\
\text { index }\end{array}$ & $\begin{array}{l}\text { Average } \\
\text { RISP }\end{array}$ & $\begin{array}{l}\text { Max scintillation } \\
\text { attenuation }(\mathrm{dB})\end{array}$ & $\begin{array}{l}\text { Max scintillation } \\
\text { index }\end{array}$ & Max RISP \\
\hline Dhaka & 23 & 1.0851 & 1.5284 & 0.0353 & $1.65 \times 10^{-5}$ & $2.16 \times 10^{-9}$ & 0.0497 & $3.27 \times 10^{-5}$ & $4.28 \times 10^{-9}$ \\
\hline Chittagong & 15 & 3.2635 & 4.022 & 0.0976 & $1.26 \times 10^{-5}$ & $1.28 \times 10^{-9}$ & 0.1202 & $19.18 \times 10^{-5}$ & $1.95 \times 10^{-8}$ \\
\hline Sylhet & 26 & 1.0938 & 1.351 & 0.0377 & $1.89 \times 10^{-5}$ & $2.47 \times 10^{-9}$ & 0.0465 & $2.88 \times 10^{-5}$ & $3.77 \times 10^{-9}$ \\
\hline Rangpur & 36 & 1.5642 & 2.318 & 0.0615 & $5.02 \times 10^{-5}$ & $6.92 \times 10^{-9}$ & 0.0911 & $11.0 \times 10^{-5}$ & $1.52 \times 10^{-8}$ \\
\hline Mymensingh & 18 & 0.9977 & 1.669 & 0.0367 & $1.79 \times 10^{-5}$ & $1.43 \times 10^{-9}$ & 0.0613 & $5.00 \times 10^{-5}$ & $4.01 \times 10^{-9}$ \\
\hline
\end{tabular}

The strength of atmospheric turbulence effect depends on the value of refractive index structure parameter (RISP). The refractive index strongly varies not only with the variation of altitude of the place, but also with geographic location, cloud cover and temperature variations [4]. The average RISP has been computed $2.16 \times 10^{-9}, 2.43 \times 10^{-9}, 1.28 \times 10^{-8}, 2.47 \times 10^{-9}, 6.92 \times 10^{-9}, 1.43 \times 10^{-9}$ and $2.54 \times 10^{-10}$ for Dhaka, Rajshahi, Chittagong, Sylhet, Rangpur, Mymensingh and Barisal respectively. The maximum average RISP has been found for Chittagong and minimum for Barisal. The typical range of RISP is $10^{-17} \mathrm{~m}^{-2 / 3}$ (considered as weak turbulence) to $10^{-12} \mathrm{~m}^{-2 / 3}$ (considered as strong turbulence) [4]. Analyzing the computed data, it can be stated that the effect of atmospheric turbulence is strong in all the selected cities.

The received signal optical power variations cause scintillation effect [4]. The average scintillation index is measured $1.65 \times 10^{-5}, 4.18 \times 10^{-5}, 1.26 \times 10^{-5}, 1.89 \times 10^{-5}, 5.02 \times 10^{-5}, 1.79 \times 10^{-5}$ and $2.5 \times 10^{-6}$ for Dhaka, Rajshahi, Chittagong, Sylhet, Rangpur, Mymensingh and Barisal respectively. The maximum average scintillation index is observed for Chittagong and minimum for Barisal. The increase of optical turbulence increases the scintillation index dramatically [4], the measured data also proves that. In calculating the attenuation due to scintillation, the link length is considered to be equal to the visibility length of each city. The maximum loss due to scintillation has been found in Chittagong with an average attenuation of $0.0976 \mathrm{~dB}$, whereas, Barisal is less affected by this attenuation. One point must be mentioned that no cities under consideration have severe attenuation effects due to atmospheric turbulence.

\section{CONCLUSION}

This work focused on the prospects and the feasibility of the emerging FSO technology from the atmospheric context of Bangladesh. As mentioned earlier that Bangladesh is entering to a new era of satellite communications soon to meet the demand of largely increasing internet and high speed data communication amenities. The necessity of deploying FSO technology is becoming crucial to meet the demand in the near 
future. Here, thorough investigation has been performed to identify the feasibility of deploying FSO technology in terms of propagation channel characterization. After analyzing the measured data, it can be stated that FSO technology is feasible for short range communications link, since the average visibility range in Bangladesh is very low which is around $4 \mathrm{~km}$ to keep the scattering attenuation in optimum range. Moreover, the analysis demonstrates that the atmospheric turbulence effect is strong in Bangladesh that can attenuate the signal quality significantly. In this circumstance, to optimize the turbulence effect antenna aperture averaging technique needs to be implemented at receiver end with greater accuracy. The measured data also shows that if it is possible to keep the atmospheric turbulence effect below the threshold value by applying effective method then FSO technology will be feasible as an alternative and effective technology in place of existing technologies for short range extremely high speed wireless communication links.

\section{ACKNOWLEDGEMENTS}

This research work was supported by Jatiya Kabi Kazi Nazrul Islam University, Bangladesh. The authors would like to thanks the University for providing the necessary funding for this research work.

\section{REFERENCES}

[1] Hennes Henniger, Otakar Wilfert, "An Introduction to Free-space Optical Communications," Journal of Radioengineering, vol. 19, No. 2, June 2010.

[2] Abdulsalam Ghalib Alkholidi and Khaleel Saeed Altowij, "Free Space Optical Communications-Theory and Practices," InTech, 2014.

[3] John Kaufmann, "Free Space Optical Communications: An Overview of Applications and Technologies," Boston IEEE Communications Society Meeting, December 2011.

[4] Arun K. Majumdar and Jennifer C. Ricklin, "Free-Space Laser communications, Principles and Advances," Number ISBN: 987-0-387-28652-5, Springer, 2008.

[5] T.H. Carbonneau, D.R. Wisley, "Opportunities and challenges for optical wireless; the competitive advantage of free space telecommunications links in today's crowded market place," in: SPIE Conference on Optical Wireless Communications, MA, 1998.

[6] Morio Toyoshima, "Trends in Laser Communications in Space," Space japan Review, (70):1-6, October/November 2010.

[7] S. Rajbhandari Z. Ghassemlooy, W. Popoola. "Optical Wireless Communications System and Channel Modelling with MATLAB,” ISBN-13:987-1-4398-5235-4. CRC Press, 2013.

[8] Goodwin F. E., "A review of operational laser communication systems," Proceedings of IEEE, 58, pp. 1746-1752, 1970.

[9] H. Elgala, R. Mesleh and H. Haas, "Indoor optical wireless communication: Potential and state-of-the-art," IEEE Communications Magazine 49(9), 56-62, 2011.

[10] BOUCHET, "Free-Space Optics-Propagation and Communication," Hermes Science Publishing, 2006.

[11] F. Nadeem, V. Kvicera, M.S. Awan, "Weather effects on hybrid FSO/RF communication link," IEEE J. Sel. Area. Commun. 27, 9 December, 2009.

[12] S. Ahmad Zabidi, W. Al Khateeb, Md. Rafiqul Islam, A.W. Naji, "The effect of weather on free space optics communication (FSO) under tropical weather Conditions," in: International Conference on Computer and Communication Engineering (ICCCE 2010), Kuala Lumpur, Malaysia, 11-13 May, 2010.

[13] S. Rajbhandari Z. Ghassemlooy, W. Popoola. "Optical Wireless Communications System and Channel Modelling with MATLAB,” ISBN-13:987-1-4398-5235-4. CRC Press, 2013.

[14] Mazin Ali, Abd Ali and Miami Abdulatteef Mohammed, "Effect of Atmospheric Attenuation on Laser Communications for Visible and Infrared Wavelengths," Journal of Al- Nahrain University, Vol.16 (3), pp. 133-140, September 2013.

[15] Julius Mohale, Michelle R. Handura, Thomas O. Olwal, and Clement N. Nyirendac, "Feasibility study of free-space optical communication for South Africa," Optical Engineering, Vol. 55(5), pp. 056108(-01-10), May 2016.

[16] Ghassemlooy Z. and Popoola W. O., "Terrestrial Free-Space Optical Communications, Mobile and Wireless Communications Network Layer and Circuit Level Design," Salma Ait Fares and Fumiyuki Adachi (Ed.), ISBN: 978-953-307-042-1, InTech, 2010.

[17] Abdulsalam Alkholidi and Khalil Altowij, "Effect of Clear Atmospheric Turbulence on Quality of Free Space Optical Communications in Western Asia," Optical Communications Systems, Dr. Narottam Das (Ed.), InTech, 2012, DOI: $10.5772 / 35186$.

[18] Hilal A. Fadhila, Angela Amphawanb, Thanaa Hussein Abda, Hamza M.R. Q1 Al-Khafaji, S.A. Aljunida, Nasim Ahmed,"Optimization of free space optics parameters: An optimum solution for bad weather conditions," Optik International Journal for Light and Electron Optics, Vol: 124, Issue: 19, PP. 3969-3973, October 2013.

[19] N. J. Veck., "Atmospheric Transmission and Natural Illumination (visible to microwave regions)," GEC Journal of Research, 3(4), 209-223, 1985.

[20] S. Bloom, E. Korevaar, "Understanding the performance of free-space optics," J.Optik. Netw. 2, 178-200, June 6, 2003. 
[21] Kazaura K., Omae, K. Suzuki, T. Matsumoto, M. Mutafungwa, E. Murakami, T. Takahashi, K. Matsumoto, H. Wakamori \& Y. Arimoto, "Performance Evaluation of Next Generation Free-Space Optical Communication System," IEICE Transaction of Electronics, E90-C, pp. 381-388, 2007.

[22] Bangladesh Metrological Department (BMD), official website: http://bmd.gov.bd/?/home/

[23] M. Gebhart and Al, "Measurement of light attenuation in dense fog conditions for optical wirelesses links," Proceedings of SPIE, vol. 581, 2005.

\section{BIOGRAPHIES OF AUTHORS}

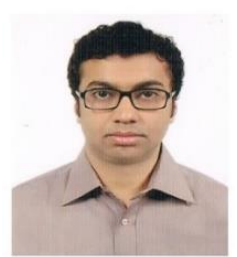

Kazi Md Shahiduzzaman is currently working as an Assistant Professor in Jatiya Kabi Kazi Nazrul Islam University, Bangladesh. He is working as an academician since 2010. He had also working experience as research student in German Aerospace Center (DLR) for 8 months during His Master's Thesis. He has completed MSc. in Electronics Engineering from HS-Bremen Germany, BSc. in Electrical and Electronic Engenerring from KUET, Bangladesh. Now He is studying Doctoral (PhD) from HUST, China. In his career, till to date he has published six (6) journal papers.

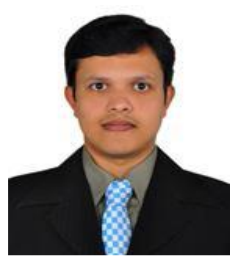

Majumder Fazle Haider is currently working as Lecturer at BRAC University, Bangladesh. Prior to joining BRAC University he served as a Research assistant at Research \& Development department of Hella KGaA Hueck \& Co. in Bremen, Germany. He completed his MSc. in Electronics and Communication Engineering from University of Applied Sciences Bremen, Germany. Mr. Haider often publishes paper in international conference and peer reviewed journals. His current research interests include energy efficient wireless communications, Free Space Optical wireless communications and mmWave communications.

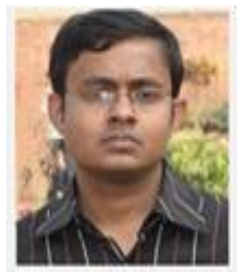

Bijoy Kumer Karmaker is currently working as an an Assistant Professor in Department of EEE at Jatiya Kabi Kazi Nazrul Islam University, Bangladesh. He is also the departmental head of that Department. He has completed MSc. in ICT from BUET, Bangladesh and BSc. in ICE from Rajshahi University, Bangladesh. In his career, till to date he has published six (6) journal papers. 